\title{
In vitro cytotoxicity of Phortress against colorectal cancer
}

\author{
ABHIK MUKHERJEE and STEWART GRAHAM MARTIN \\ Department of Oncology, University of Nottingham, City Hospital, Nottingham, NG5 1PB, UK
}

Received April 14, 2006; Accepted June 7, 2006

\begin{abstract}
Phortress is a novel benzothiazole compound with activity concentrated in certain breast, ovarian and renal cancer cell lines. Its anti-angiogenic effects are unknown. In this study, the in vitro anti-angiogenic effects of Phortress were screened for and results compared with two control drugs, paclitaxel and fumagillin. In vitro anti-angiogenic activity was examined by MTS assays, growth curves and clonogenic survival assays on human umbilical vein endothelial cells (HUVEC). In addition and as a comparator, effects were examined on MRCV fibroblasts and also the MCF7 breast cancer cell line, shown to be sensitive on the NCI60 panel and 3 colorectal cancer cell lines (HT29, SW480 and SW620) that were reportedly insensitive. Effects on endothelial tube differentiation were assessed by the Matrigel assay. Phortress had no effect on HUVEC and MRCV cell proliferation and survival. Unlike paclitaxel and fumagillin, Phortress did not inhibit endothelial tube differentiation. Phortress therefore exhibits no in vitro anti-angiogenic activity. As expected, Phortress was cytotoxic to MCF7 breast cancer cells, but unexpectedly, Phortress was also potent against colorectal cancer cells in clonogenic survival and cell growth (growth curves but not MTS assay) end-points. The efficacy of Phortress against colorectal cancer cells in the current study confirms that the spectrum of activity of Phortress may be wider than previously thought.
\end{abstract}

\section{Introduction}

Phortress (Fig. 1) is a novel anti-tumour agent belonging to the benzothiazole family, the evolution of which has been extensively reviewed by Bradshaw and Westwell (1). On the NCI60 panel (Fig. 2), the $\mathrm{GI}_{50}$ (50\% growth inhibitory concentration) data indicate that MCF7 and T47D breast, TK-10 renal, IGROV-1 and OVCAR-5 ovarian and NCI-H226

Correspondence to: Dr S.G. Martin, University of Nottingham, Department of Clinical Oncology, City Hospital, Nottingham, NG5 1PB, UK

E-mail: stewart.martin@nottingham.ac.uk

Key words: chemotherapy, colorectal cancer, Phortress, anti-angiogenesis and NCI-460 non-small cell lung cancer cells are sensitive to Phortress in vitro. Colorectal cell lines appear to be relatively insensitive with only 1 (HCC2998) of the six colorectal cell lines being moderately sensitive (1).

The mechanism of action of Phortress is thought to involve the aryl hydrocarbon receptor (AhR) (2). The drug is converted to the active form 5F 203 in plasma, and undergoes nuclear translocation after AhR binding (3). Nuclear translocation leads to cytochrome p450 CYP1A1 induction (4), generation of a reactive intermediate (probably a nitrenium species) and formation of DNA adducts in sensitive cells $(5,6)$ leading to cell death. NCI results indicate that there is a significant correlation between drug sensitivity and induced CYP1A1. This is confirmed by cDNA microarrays for MCF7 cells treated with DF $203(1 \mu \mathrm{M}, 24 \mathrm{~h})$, which showed 10-fold up-regulation of both CYP1A1 and CYP1B1 (1). For in vivo studies, MCF7 (Phortress-sensitive) and MDA-MB-435 (Phortress-insensitive) tumours were implanted into opposite flanks of the same mouse. Significant anti-tumour activity was observed only for the MCF7 xenografts (5). Phortress is now in phase I clinical trials in the UK. No information is currently available whether the drug exerts any tumour growth inhibitory effects via anti-angiogenic mode of action in addition to the wellcharacterised anti-tumour cell cytotoxicity.

The present study aimed at evaluating the in vitro antiangiogenic activity of Phortress. Activity of the drug against breast (sensitive on the NCI60 panel) and colorectal cells (insensitive on the NCI60 panel) were chosen as comparators in assays. Preliminary results surprisingly indicated that dependent upon the assay used in evaluation, colorectal cells were sensitive to Phortress and hence the study focussed on an in depth characterisation of such effects.

\section{Materials and methods}

Drugs. Phortress was a gift from Professor Malcolm Stevens and team, Dr T.D. Bradshaw and Dr A.D. Westwell, School of Pharmacy, University of Nottingham, UK. Paclitaxel (Sigma) and fumagillin (Sigma) were chosen as control drugs to optimise experiments and compare results against.

HUVEC isolation. Human umbilical vein endothelial cells (HUVEC) were isolated from umbilical cords obtained from the Department of Obstetrics, City Hospital, Nottingham, by the collagenase perfusion technique (7), detailed in Mukherjee et al (8). All experiments with HUVEC were performed on tissue culture plates/petri dishes etc. that had been pre-coated with $0.2 \%$ gelatin. 
<smiles>[Y6]c1cc(-c2nc3cc(F)ccc3s2)ccc1NC(=O)[C@@H](N)[C@@H](N)C(C)(C)C</smiles>

Figure 1. Chemical structure of Phortress.

Cell culture. Two 'normal' cell types, HUVEC, and MRCV lung fibroblasts (ECACC) were used. The colorectal cancer cell lines HT29, SW480, SW620 and the breast cancer cell line MCF7 (American Type Culture Collection) were chosen for this study. Media formulations, as described previously by Mukherjee et al (8), were used for cell culture. HT29 cells were used between passage 140-150, SW480 between 110-120, SW620 between 100-110, MCF7 between passage 20 and 30, HUVEC between passage 2 and 6, and MRCV between 22-26.
Cell proliferation assays

MTS assay. Assays were performed as optimised and described previously by Mukherjee et al (8). Twenty-four hours following seeding cells in 96-well plates, $20 \mu \mathrm{l}$ of $10 \mathrm{x}$ drug concentration was added to a triplicate of wells to achieve the drug concentration in a final volume of $200 \mu 1$. Medium only or vehicle only $(20 \mu \mathrm{l})$ (DMSO) were added to controls. After $72 \mathrm{~h}$ of incubation, $40 \mu \mathrm{l}$ of MTS-PES reagent (Promega, Southampton, UK) were added to each well and incubated for a further $3 \mathrm{~h}$ for colour development. The incubation time was prolonged to $96 \mathrm{~h}$ for SW620 and $120 \mathrm{~h}$ for SW480 to ensure at least one doubling of absorbance. The time for development of formazan was also increased for these cell lines to $4 \mathrm{~h}$ instead of $3 \mathrm{~h}$. The absorbance was read from the plates at $492 \mathrm{~nm}$ on a plate reader. Absorbance levels from drug treated cells and untreated controls were corrected against medium only blank controls. The mean absorbance of drug treated wells was expressed as a percentage of non-treated controls to calculate the percentage proliferation status $(9,10)$.

\begin{tabular}{|c|c|c|}
\hline Cell Line & Lopin Glsa & Gls \\
\hline $\begin{array}{l}\text { Leukemiik } \\
\text { K-552 } \\
\text { MOLT-4 } \\
\text { RPM1-8226 } \\
\text { SR }\end{array}$ & $\begin{array}{l}-5.64 \\
-6.00 \\
-5.61 \\
-6.25\end{array}$ & \\
\hline $\begin{array}{l}\text { AS49/ATCC } \\
\text { HOP-62 } \\
\text { HOP }-92 \\
\text { NC1-H226 } \\
\text { NCIH23 } \\
\text { NCl-H322M } \\
\text { NCl-460 }\end{array}$ & $\begin{array}{l}-5.77 \\
-5.20 \\
-4.82 \\
-6.81 \\
-5.68 \\
-5.51 \\
-7.15\end{array}$ & \\
\hline $\begin{array}{l}\text { COLO 205 } \\
\text { HCC-2998 } \\
\text { HCT-116 } \\
\text { HCT-15 } \\
\text { HT29 } \\
\text { SW-620 }\end{array}$ & $\begin{array}{l}-5.48 \\
-6.13 \\
-5.54 \\
-5.28 \\
-5.49 \\
-5.44\end{array}$ & $E$ \\
\hline $\begin{array}{l}\text { SF-258 } \\
\text { SF-539 } \\
\text { SNB-19 } \\
\text { SNB-75 } \\
\text { U251 }\end{array}$ & $\begin{array}{r}-5.17 \\
-4.85 \\
-4.87 \\
-5.79 \\
-5.67\end{array}$ & $=$ \\
\hline $\begin{array}{l}\text { MELOTOM } \\
\text { LOX IMVI } \\
\text { MALME-3M } \\
\text { MI4 } \\
\text { SK-MEL-2 } \\
\text { SK-MEL-28 } \\
\text { SK-MEL-5 } \\
\text { UACC-257 } \\
\text { UACC-62 }\end{array}$ & $\begin{array}{l}-5.70 \\
4.76 \\
-5.67 \\
-5.60 \\
-4.65 \\
-4.81 \\
-4.80 \\
-4.85\end{array}$ & \\
\hline $\begin{array}{l}\text { IGROVI } \\
\text { OVCAR-3 } \\
\text { OVCAR-4 } \\
\text { OVCAR-5 } \\
\text { OVCAR-8 } \\
\text { SK-OV-3 }\end{array}$ & $\begin{array}{r}<.800 \\
-4.97 \\
-5.69 \\
6.90 \\
4.99 \\
4.79\end{array}$ & \\
\hline $\begin{array}{l}\text { T86-0 } \\
\text { A498 } \\
\text { ACFN } \\
\text { RXF 393 } \\
\text { SN 12C } \\
\text { TK-10 } \\
\text { Uo-31 }\end{array}$ & $\begin{array}{l}-5.39 \\
+.90 \\
-5.22 \\
-5.14 \\
-4.91 \\
-7.76 \\
-5.51\end{array}$ & \\
\hline $\begin{array}{l}\text { PC.3 } \\
\text { DU.145 }\end{array}$ & $\begin{array}{r}4.90 \\
4.79 \\
\end{array}$ & \\
\hline $\begin{array}{l}\text { MCF7 } \\
\text { NCVADR-RES } \\
\text { MDA-MB-231/ATCC } \\
\text { HS S7ET } \\
\text { MDA-MB-435 } \\
\text { MDA-N } \\
\text { BT-549 } \\
\text { T.47D }\end{array}$ & 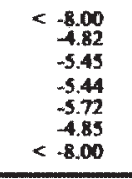 & \\
\hline $\begin{array}{l}\text { MOMID } \\
\text { Dellui } \\
\text { Rengt }\end{array}$ & $\begin{array}{l}-5.60 \\
-2.40 \\
-3.35\end{array}$ & \\
\hline
\end{tabular}

Figure 2. NCI-60 GI S0 $_{0}$ graph for Phortress [1] (with due permission from Bradshaw TD and Westwell A). 
MTS assays: HUVEC

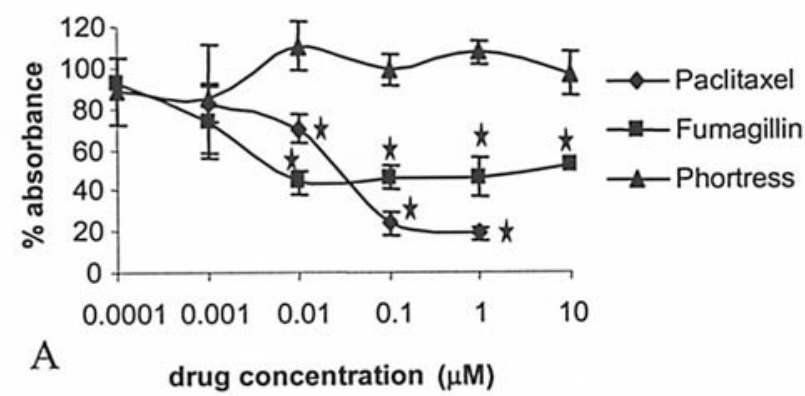

Growth assays: HUVEC

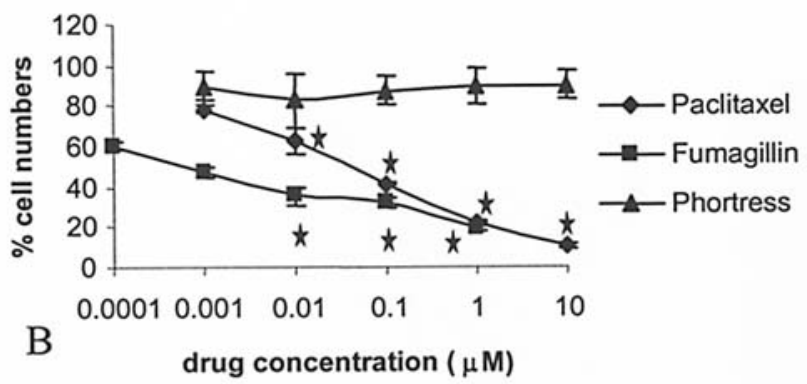

\% survival: HUVEC

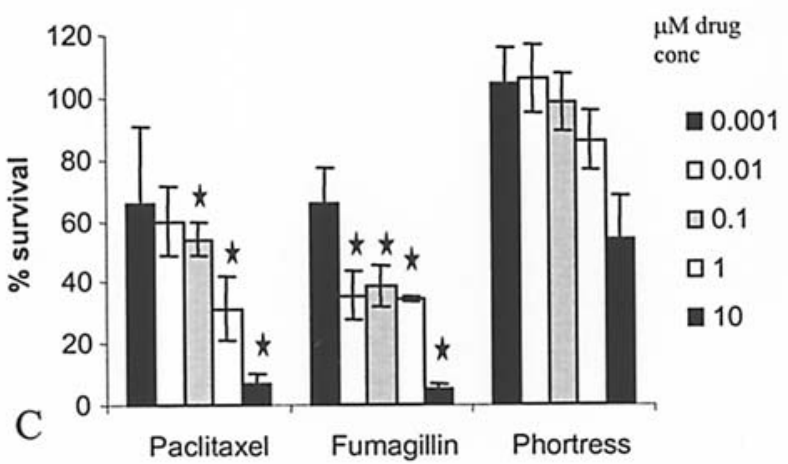

Figure 3. Effects of drugs (72-h incubation) on HUVEC. (A) MTS assays. (B) Growth assays (data points in duplicate). (C) Clonogenic survival assays (PE: HUVEC $40 \pm 10 \%$, HUVEC $40 \pm 10 \%$ and HUVEC $15 \pm 5 \%$, for paclitaxel, fumagillin and Phortress experiments). All data points were in triplicate (except for growth assays), and experiments repeated at least twice. Error bars represent standard error of means.

Growth assays. The proliferation status of cells was also assessed by simple counting of cell number after treatment with drugs (11). Cells $\left(10^{5}\right)$ of each cell line were plated out on 6-well tissue culture plates (Corning, High Wycombe, UK) in a volume of $3 \mathrm{ml}$ of medium. The cells were allowed to attach overnight, and then exposed to drugs for 24,48 or $72 \mathrm{~h}$. A pair of wells were washed with PBS, trypsinised and counted before drug treatment to give the number of cells before the addition of drug. This was taken as the $0 \mathrm{~h}$ timepoint. Further duplicate readings were conducted at 24, 48 and $72 \mathrm{~h}$ after the addition of drug and experiments repeated at least twice.
Cell survival assays. To measure reproductive integrity post drug-treatment, assays were performed according to the protocol of Liebmann et al (12) with some modifications. Petri dishes (100 mm) (Corning, High Wycombe, UK) were plated with $5 \times 10^{5}$ cells in $10 \mathrm{ml}$ of media or $60 \mathrm{~mm}$ petri dishes were plated with $1.8 \times 10^{5}$ cells in $3.5 \mathrm{ml}$ of media. The cells were allowed to attach for $24 \mathrm{~h}$. Media was aspirated off and the exponentially growing cells were then exposed to drug for $72 \mathrm{~h}$, following which they were trypsinised and plated out for colony formation. Incubation time was 4 weeks for all tumour cell lines except SW620 (3 weeks), 2 weeks for fibroblasts and 10 days for HUVEC. Finally, colonies were fixed with methanol (Fisher Scientific, Loughborough, UK) and stained with $1 \%$ crystal violet (Sigma) vide a protocol modified from Freshney (13). Colonies were counted by eye and confirmation by microscopy carried out as necessary. Any cluster of cells greater than 50 in number was counted as a colony. All survival points were in triplicate and experiments repeated at least twice.

Tube formation studies on Matrigel. The method was adapted from Dicker et al (14). $0.2 \%$ gelatinized $100 \mathrm{~mm}$ petri dishes were plated with $5 \times 10^{5}$ HUVEC cells in $6 \mathrm{ml}$ of medium. The cells were allowed to attach for $24 \mathrm{~h}$. The medium was aspirated off and exponentially growing cells were then exposed to $6 \mathrm{ml}$ of the $\mathrm{IC}_{50}$ dose of control drugs paclitaxel, fumagillin or Phortress for $72 \mathrm{~h}$. For each drug treated condition, or control, 50,000 cells, in $200 \mu 1$ of medium, were then added to wells of a 24 well plate pre-coated with Matrigel at room temperature for $1 \mathrm{~h}$. Cells were then incubated at $37^{\circ} \mathrm{C}$ and $5 \% \mathrm{CO}_{2}$ for $48 \mathrm{~h}$. Photographs were taken for assessment of tube formation on Matrigel at $24 \mathrm{~h}$ post-plating.

Statistical analysis. The Student's t-test was used to calculate probability values and $\mathrm{p}<0.05$ was considered to be statistically significant (indicated by asterisk on graphs).

\section{Results}

MTS assay. MTS assays show that the control drug paclitaxel decreases the proliferation of endothelial (Fig. 3A) as well as breast and colorectal cell lines (Fig. 4A). Fumagillin, on the other hand, only decreases the proliferation of endothelial cells, at both low and high doses (Fig. 3A). Effects on tumour cell proliferation, in contrast, are evident only at a very high dose of $10 \mu \mathrm{M}$, and only for SW480 and SW620 (Fig. 4B). There was no effect of Phortress on endothelial cell proliferation in the MTS assay (Fig. 3A). Phortress decreased the proliferation of MCF7 breast cancer cells but colorectal cancer cell lines were relatively resistant (Fig. 4C). Of them, only $\mathrm{SW} 480$ has an $\mathrm{IC}_{50}$ of $\sim 5 \mu \mathrm{M}$. These results match the $\mathrm{GI}_{50}$ data of the NCI60 panel, which demonstrate that breast, but not colorectal cancer cell lines, are sensitive to Phortress. The $\mathrm{IC}_{50}$ value quoted in the literature for Phortress and MCF7 is $0.039 \mu \mathrm{M}$ (3). The current results $\left(\mathrm{IC}_{50} \sim 0.05 \mu \mathrm{M}\right)$ are comparable to such values.

Growth assay. As expected, paclitaxel decreased the proliferation of endothelial (Fig. 3B) as well as breast and colorectal cells in growth assays (Fig. 5A). Fumagillin was most 
MTS assay results: Paclitaxel (72hrs)

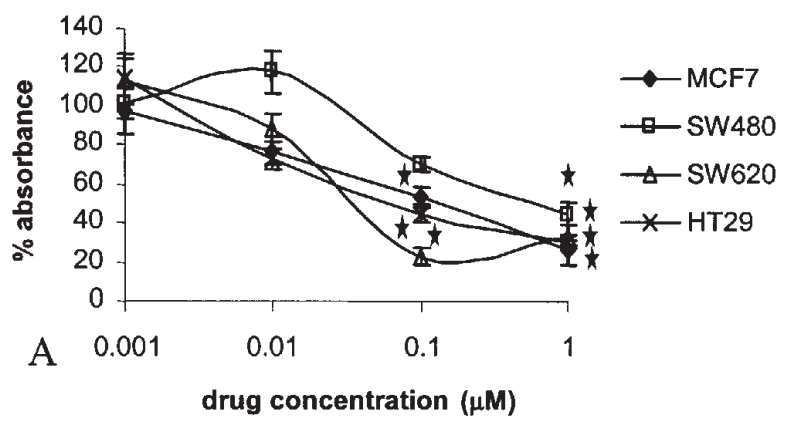

MTS assay results: Fumagillin (72hrs)

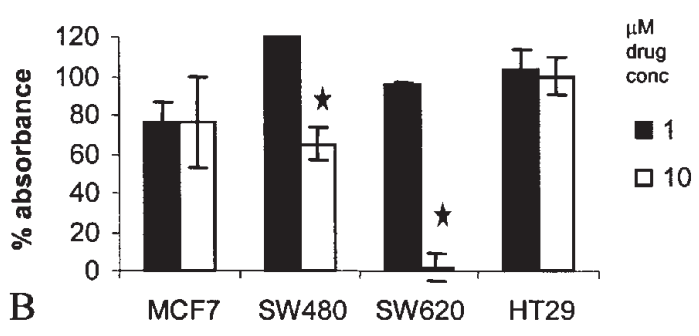

MTS assay results: Phortress (72hrs)

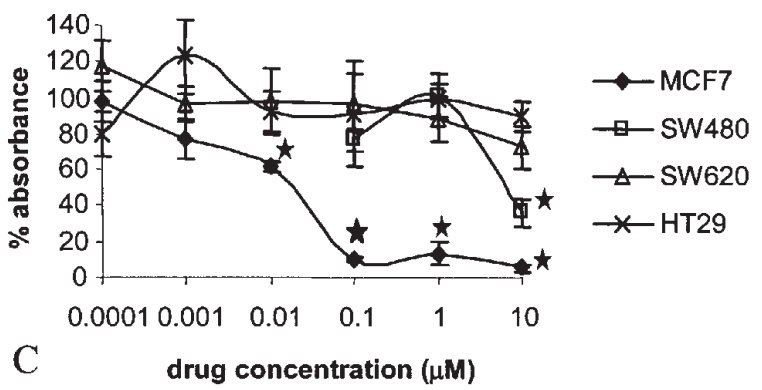

Figure 4. MTS assay results, cancer cells. Percentage absorbance as compared to controls after $72 \mathrm{~h}$ of treatment with (A) paclitaxel (B) fumagillin and (C) Phortress for HT29 (X), SW480 $(\square)$, SW620 $(\triangle)$, MCF7 $(\bullet)$. Data points were in triplicate in individual experiments, repeated at least twice, and error bars represent standard error of means.

potent against endothelial cells with an $\mathrm{IC}_{50}$ of $\sim 0.5 \mathrm{nM}$ (Fig. 3B). Though relatively ineffective for colorectal cells in MTS assays, $1 \mu \mathrm{M}$ fumagillin caused a significant decrease in cell number $(\sim 65 \%$ for HT29, 50\% for SW620 and $70 \%$ for SW480) (Fig. 5B). In contrast to MTS assays, growth assays for Phortress also revealed inhibition of colorectal cell proliferation after 72-h incubation (Fig. 5C). Temporal curves for colorectal cell lines show that the maximal effect is at the 72-h time-point, with little effect at 24 and 48 h (Fig. 6). Phortress may thus require longer incubation periods against colorectal cancer cell lines. MCF7 cells were most sensitive to Phortress (Fig. 5C) but HUVEC were resistant (Fig. 3B). The discrepancy between MTS and growth curve results was also observed for both Phortress and fumagillin.
$\%$ cell numbers: Paclitaxel (72hrs)

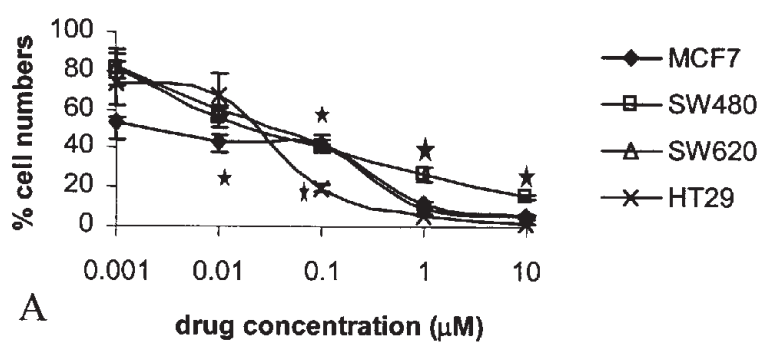

$\%$ cell numbers: Fumagillin (72hrs)

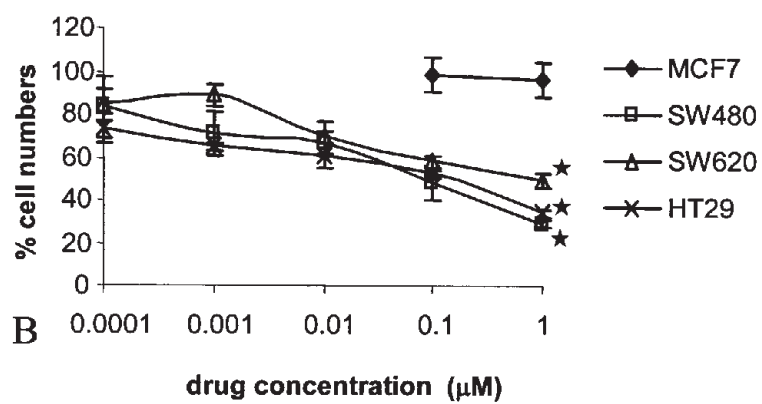

$\%$ cell numbers: Phortress (72 hrs)

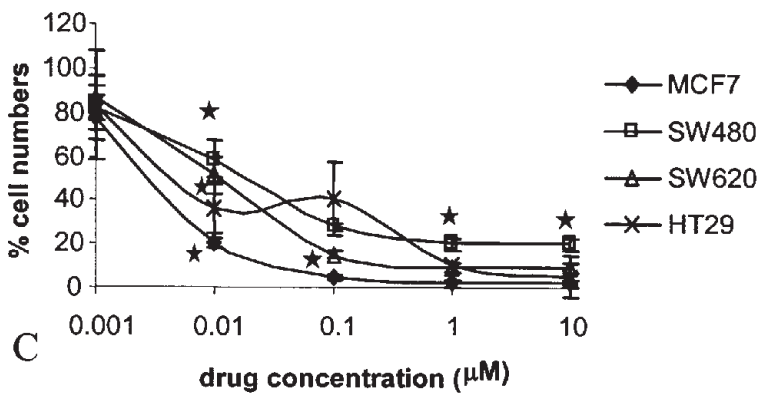

Figure 5. Growth assay results, cancer cells. Percentage cell numbers as compared to controls after $72 \mathrm{~h}$ of treatment with (A) paclitaxel (B) fumagillin and (C) Phortress for HT29 (X), SW480 ( $\square$ ), SW620 (₫), MCF7 (•). Data points were in triplicate in individual experiments, repeated at least twice, and error bars represent standard error of means.

Clonogenic survival assays. Paclitaxel was cytotoxic for both endothelial (Fig. 3C) and tumour cells (Fig. 7A) as demonstrated by the decrease in cell survival. In addition to HUVEC (Fig. 3C), fumagillin was also cytotoxic to colorectal cells such as HT29 (Fig. 7B). Clonogenic survival assays with Phortress demonstrate that the effect of the drug on both colorectal and breast cancer cell lines is cytotoxic (Fig. 7C). In terms of sensitivity, MCF7 and HT29 were the most sensitive $\left(\mathrm{IC}_{50} \sim 0.01 \mu \mathrm{M}\right)$ followed by SW620 $\left(\mathrm{IC}_{50} \sim 0.1 \mu \mathrm{M}\right)$ and SW480 (IC50 0.5 $\mu \mathrm{M}$ ). HUVEC were resistant to the drug even at a high dose of $1 \mu \mathrm{M}$ (Fig. 3C). Only at a very toxic dose of $10 \mu \mathrm{M}$, there was decrease in clonogenic survival of HUVEC; but they were still resistant in comparison to other cells (Figs. 3C and 7C). 
SW480

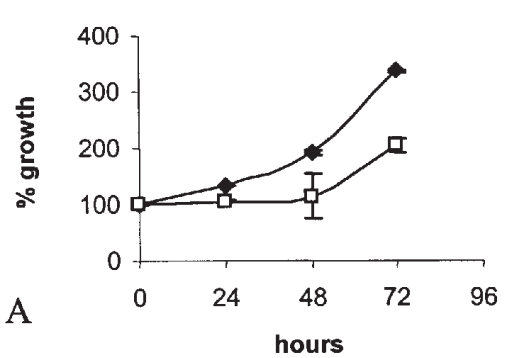

SW620

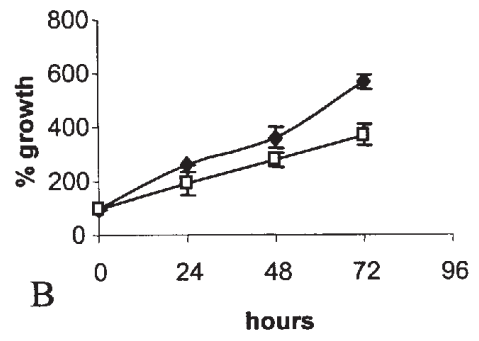

HT29

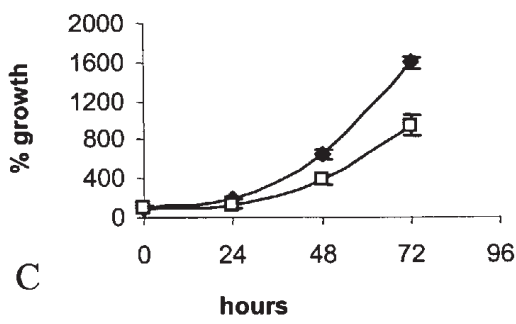

Figure 6. Temporal plots showing effects of $0.1 \mu \mathrm{M}\left(\sim \mathrm{IC}_{50}\right)$ Phortress ( $\square$ ) and untreated controls ( $\left.\bullet\right)$ on SW480 (A), SW620 (B), HT29 (C) at 24, 48 and 72-h time-points. Results from one representative experiment: \% growth compared to 0-h time-point (time of drug addition) was plotted in duplicate and error bars represent standard deviation.

$\%$ survival: Paclitaxel (72hrs)

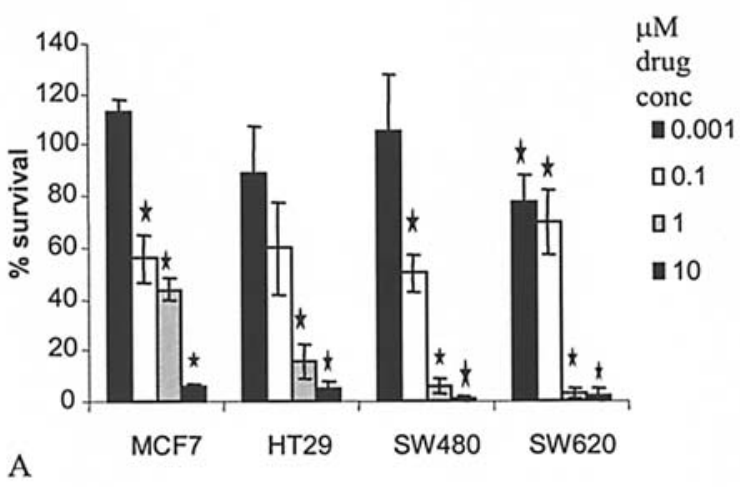

$\%$ survival: Fumagillin (72hrs)

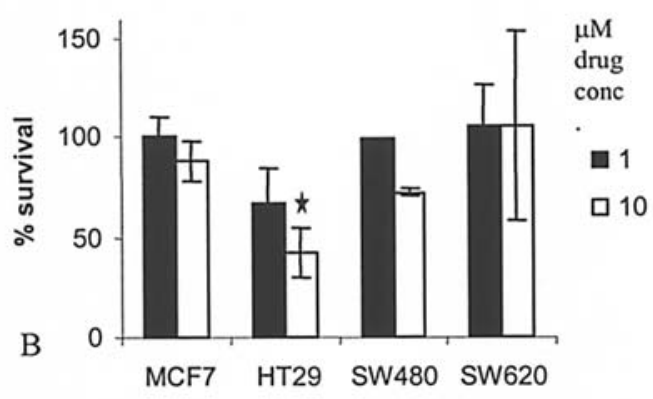

\% survival: Phortress (72hrs)

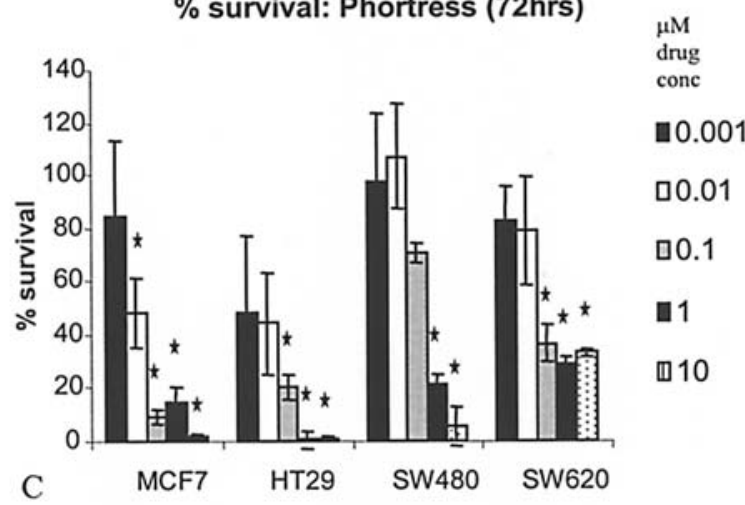

Figure 7. Mean clonogenic cell survival of cancer cells treated with (A) paclitaxel (B) fumagillin and (C) Phortress. Each data point was in triplicate and error bars represent standard error of means. Plating efficiencies of individual cell lines for each dataset with standard error were as follows: (A) MCF7-40 $\pm 10 \%$;

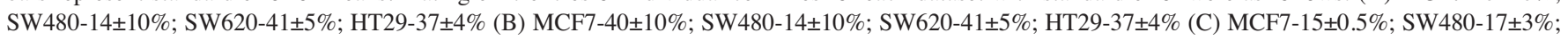
SW620-8.5 $\pm 1.1 \%$; HT29-11.33 $\pm 3.2 \%$. 
MTS assay results: Fibroblasts + Drugs

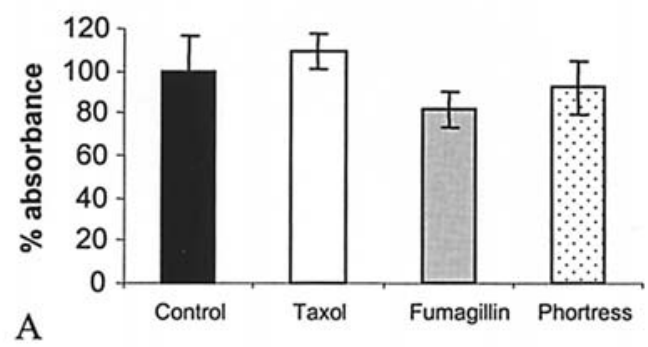

Cell numbers: Fibroblasts + Drugs

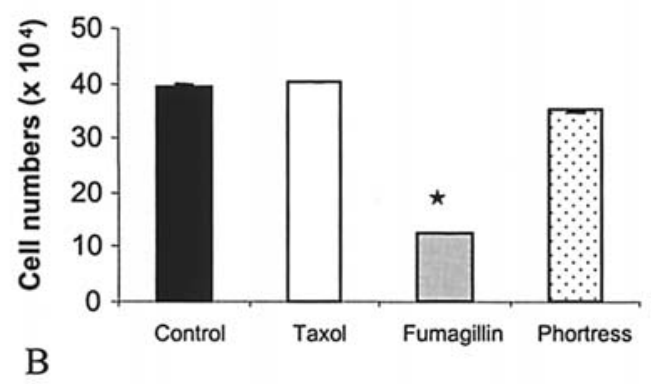

$\%$ cell survival: Fibroblasts and Drugs

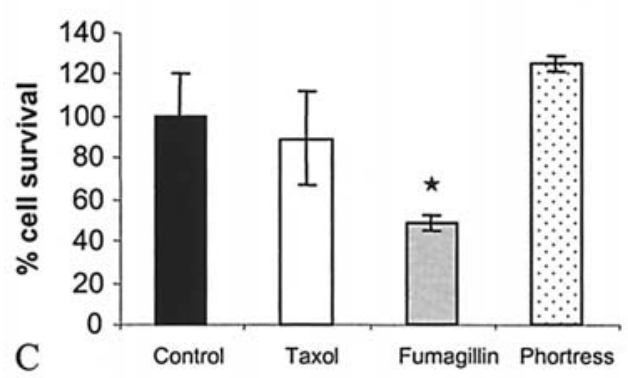

Figure 8. Effects of drugs $(0.1 \mu \mathrm{M}$ paclitaxel, $0.01 \mu \mathrm{M}$ fumagillin and $0.1 \mu \mathrm{M}$ Phortress, 72-h incubation) on MRCV fibroblasts. (A) MTS assay. (B) Growth assay (data points in duplicate). (C) Clonogenic survival assay (PE: $30 \pm 4 \%$ ). All data points were in triplicate (apart from growth assay) and experiments repeated at least twice; error bars represent standard deviation.

Sensitivity of MRCV fibroblasts. To further investigate for differential sensitivity to normal cells, the effects of the drugs (at cytotoxic doses: $0.1 \mu \mathrm{M}$ paclitaxel, $0.01 \mu \mathrm{M}$ fumagillin and $0.1 \mu \mathrm{M}$ Phortress) were examined by MTS, growth assays and clonogenic survival assays on MRCV fibroblasts (Fig. 8). Fibroblasts were resistant to both paclitaxel and Phortress in terms of proliferation (Fig. 8A and B) as well as clonogenic survival (Fig. 8C). Phortress thus appears to be highly tumour specific in that both fibroblasts and endothelial cells are resistant. In contrast, fumagillin decreased both proliferation (B) and clonogenic survival (C) of MRCV fibroblasts. As observed for some tumour cells, MTS (A) and growth assays (B) yielded opposing results for fumagillintreated fibroblasts.

Effects on endothelial tube differentiation. Angiogenesis is a stepwise process where endothelial cells must differentiate into tubes to form new vessels. The formation of tube-like vessels on Matrigel can therefore be used to assess compounds that either stimulate or inhibit angiogenesis (15). Phortress did not inhibit endothelial differentiation at a dose of $10 \mu \mathrm{M}$ at either 24 or 48 -h post-plating (data not shown). In contrast control drugs, paclitaxel and fumagillin, inhibited endothelial differentiation at the $\mathrm{IC}_{50}$ dose, as evident from tubal abortion at both 24 and 48-h post-plating (data not shown).

\section{Discussion}

This project set out to screen for in vitro anti-angiogenic activity of the novel drug Phortress. The in vitro anti-angiogenic screen included MTS, growth, clonogenic survival and Matrigel assays, comparable to the NCI screen that includes HUVEC growth inhibition (crystal violet assay, 72-h drug exposure), Matrigel assay and migration assays in a Boyden chamber. The choice of control drugs for the study, fumagillin and paclitaxel, parallels that of the NCI who utilises TNP-470, a fumagillin analogue, and paclitaxel as control drugs in the anti-angiogenic screen. Since the NCI60 panel screen indicates that breast and colorectal cancer cells were relatively sensitive and insensitive respectively to Phortress, they were chosen as comparators in the current screen. Our anti-tumour cell screen included both MTS assays and growth curves for proliferation, and clonogenic survival assays for reproductive integrity.

Primary and metastatic breast cancer and drug-refractory ovarian cancer are sensitive to paclitaxel. It acts by inhibiting microtubule depolymerisation thereby blocking cells in the $\mathrm{G}_{2} / \mathrm{M}$ phase of the cell cycle. The effect of paclitaxel on colorectal cancer is less documented, as it is not clinically effective for this tumour. However, as with the current study, in vitro efficacy in colorectal cancer has been reported in studies by Banerjee et al (16) and Valenti et al (17). Paclitaxel also inhibited endothelial cell proliferation $\left(\mathrm{IC}_{50} \sim 0.05 \mu \mathrm{M}\right)$, similar to that documented in the studies of Belotti et al (18) and Iwahana et al (19). Clonogenic survival assays demonstrated the anti-endothelial effect to be cytotoxic (at 0.1-10 $\mu \mathrm{M}$ ). Paclitaxel also aborted tube differentiation on Matrigel and, as expected, inhibits the angiogenic cascade. MRCV fibroblasts were relatively resistant to $0.1 \mu \mathrm{M}$ paclitaxel.

The second control drug fumagillin is recognised as an antiangiogenic agent (20). Its $\mathrm{IC}_{50}$ for endothelial cell proliferation was $\sim 0.5 \mathrm{nM}$ from growth curve experiments. In the MTS assay, the $\mathrm{IC}_{50}$ was on a plateau range between 0.01 and $10 \mu \mathrm{M}$. Fumagillin blocks the cell cycle in $\mathrm{G}_{1}$, and a plateau response is quite characteristic of a cell cycle phase specific agent (21). There was no effect on MCF7 cell proliferation. The $\mathrm{IC}_{50}$ for colorectal cell lines $(\sim 0.5 \mu \mathrm{M})$ was higher than that for HUVEC $(0.005 \mu \mathrm{M})$. Anomalies between MTS assay and growth curve results were observed for colorectal cancer cell lines, with the former failing to show significant response even at very high doses. The reasons for such differences could not be fully explained. From clonogenic survival assays, fumagillin was cytotoxic to HUVEC at concentrations ranging from $0.001 \mu \mathrm{M}$ to $10 \mu \mathrm{M}$. HT29 cells showed decreased clonogenic survival with fumagillin at high doses. Thus the effect of fumagillin on colon cancer cell lines such as HT29 may be cytotoxic. Although thought of as a 'pure' anti-angiogenic 
agent, similar cytotoxic effects on human glioblastoma cells have been reported for the fumagillin analogue TNP-470 (22). Investigating normal cell sensitivity, MRCV fibroblast cell numbers and clonogenic survival were grossly decreased with fumagillin treatment.

On the NCI60 panel, of the six colon cancer cell lines, only HCC 2998 was weakly sensitive to Phortress. Two of the lines used in the current study (HT29 and SW620) were reportedly resistant. The current study showed that Phortress was highly potent against MCF7 breast cancer cell lines with an $\mathrm{IC}_{50}$ in the nanomolar range, corroborating results of Bradshaw et al (3). MTS assays showed little effect of Phortress on the colorectal cancer cell lines. This agrees with the results of the NCI panel. However, subsequent growth assays revealed that Phortress may also decrease the proliferation of colorectal cell lines. This issue of discrepancy between MTS assay and growth assays (also observed with fumagillin) cannot be fully explained. It may be related to the levels of dehydrogenase enzymes in the cell lines, and their possible interactions with the drugs. The NCI anti-tumour cell screen is assessed at the 48-h time-point, whereas Phortress showed greatest effects in growth assays at the 72-h timepoint. Thus novel drugs screened against the NCI panel should be further tested at multiple time-points. The growth assay results were in concordance with those of clonogenic survival experiments, confirming cytotoxic effects against colorectal cells. This suggests that the range of activity of Phortress may extend beyond cell lines predicted by the NCI60 panel. Neither growth assays nor clonogenic survival assays on their own are sufficient to characterise a compound. The short incubation period of growth assays is criticised as not predicting clinical response and do not measure cell kill. On the other hand, clonogenic assays measure reproductive integrity and hence cytotoxicity. Yet, growth inhibition assays have their advantages. Therapeutic damage induced in isogenic sets of cells differing by a gene may lead to rapid apoptosis in one cell population but not in others, reflecting differential sensitivity. Clonogenic survival, however, may be equally inhibited (23). Colorimetric assays such as the MTS and $\mathrm{SRB}$, have advantages of low intra-test variation between data points $(9,10)$ but are only indirect measures of cell proliferation. Counting of cell numbers, though laborious, may be more beneficial as a primary screen, as evident from current results with both Phortress and fumagillin. This method, like colorimetric assays, however fails to distinguish between cytostatic and cytotoxic effects. Though the NCI attempts to delineate such effects, by calculating $\mathrm{GI}_{50}$ (dose causing 50\% growth inhibition), TGI (dose causing total growth inhibition) and $\mathrm{LC}_{50}$ (dose causing 50\% lethality) values for drugs tested, these may be considered as preliminary indicators only. In fact for Phortress, the $\mathrm{GI}_{50}$ and $\mathrm{LC}_{50}$ data are very discrepant. Colorectal cell lines are relatively resistant to Phortress as compared to breast cancer cell lines on the NCI GI ${ }_{50}$ graph (Fig. 2). However, the $\mathrm{LC}_{50}$ data (Dr T.D. Bradshaw, University of Nottingham, unpublished data) indicates that some colorectal cells such as KM112 and SW620 may be sensitive while HT29, resistant. Breast cancer cells such as MCF7, against which Phortress is active even in in vivo models, are surprisingly relatively resistant on the $\mathrm{LC}_{50}$ panel. Clonogenic assay results in the current report show that Phortress is cytotoxic for MCF7, HT29, SW620 and SW480 cells. This justifies considering different endpoints such as inhibition of growth and clonogenic survival when assessing drug effects.

The cytochrome CYP1A1 system has been thought to be involved in Phortress bioactivity. Bradshaw and Westwell (1) have reported the induction of CYP1A1 protein in the sensitive cell line MCF7 whereas resistant cell lines (e.g. MDA-MB435) lack both constitutive and inducible expression of CYP1A1. The differential between cancer cell lines in their sensitivity to Phortress may be related to their constitutive and inducible CYP1A1 activity. In contrast, HUVEC were resistant to Phortress. This could indicate differential metabolic uptake or low CYP1A1 levels in endothelial cells. However, CYP1A1 has been induced in HUVEC following B-napthoflavone treatment (24) and in PAEC (porcine aorta endothelial cells) after treatment with TCDD or benzopyrene $(25,26)$ and so Phortress would be expected to induce CYP1A1 in endothelial cells and decrease survival. Instead, endothelial cells are relatively resistant. There are a variety of possible explanations. Different ligands may modify the induction response. Cells sensitive to benzothiazoles often show expression of CYP1B1 in addition to CYP1A1, which may also play a critical role in determining relative cell sensitivity (27). DF 203 (a member of the benzothiazole family) resistant cells (e.g. MDA-MB-435) may have constitutive nuclear localisation of the aryl hydrocarbon receptor, AhR, involved in CYP1A1 induction (28). Differential localisation, function and saturation of this receptor may modulate drug efficacy. Also for activation, the prodrug Phortress must be degraded to its active form in cells, and the AhR ubiquitinated during pathway activation (28). Elevated acetylating enzymes in cells are known to have a role in acquired resistance to benzothiazole predecessors of Phortress (CJM 126) (29); this phenomenon may underlie endothelial resistance. Phortress has no effect on the tubal differentiation of HUVEC on Matrigel. In its screening for anti-angiogenic compounds, the NCI recommends in vivo investigation for only those drugs that show activity in one of the three assays of growth inhibition, tube formation and chemotaxis. With no effects either on endothelial proliferation, clonogenicity or differentiation, it seems unlikely that Phortress will have anti-angiogenic effects.

From the present study, Phortress appears to be a promising drug for both breast and colorectal cancer. MRCV fibroblasts and HUVEC are resistant to Phortress, both in proliferation and cell survival assays. This evidence is consistent with the tumour specificity of Phortress. Its activity on breast cancer cells is comparable to that of paclitaxel, a drug currently used clinically. The in vivo anti-tumour activity of Phortress has also been compared to doxorubicin in breast cancer xenograft studies (30). Phortress was equipotent in 6, less active in 2 and better in 1 of the 9 xenograft models examined. Results from phase I clinical trials in breast cancer are now awaited. However, it has the potential to be also effective against colorectal cancer. The next step would be to monitor CYP1A1 and CYP1B1 expression and DNA adduct formation in colorectal tumour cells following Phortress administration, as these may serve as biomarkers for the identification of sensitive tumour types. Finally, the efficacy must be validated using in vivo models. 
While in vitro results may not always correlate with in vivo effects, initial characterisation of novel agents should be conducted in appropriate in vitro models. The end-points considered in these assays should be as comprehensive as possible or, as indicated in the current study, there is the potential that some drugs may be untested in tumours for which they could be highly effective.

\section{Acknowledgements}

The authors acknowledge Professor Malcolm Stevens, Dr Tracey Bradshaw and Dr Andrew Westwell for collaboration and critical appraisal of the manuscript.

\section{References}

1. Bradshaw TD and Westwell AD: The development of the antitumour benzothiazole prodrug, Phortress, as a clinical candidate. Curr Med Chem 11: 1009-1021, 2004.

2. Trapani V, Patel V, Leong CO, et al: DNA damage and cell cycle arrest induced by 2-(4-amino-3-methylphenyl)-5-fluorobenzothiazole (5F 203, NSC 703786) is attenuated in aryl hydrocarbon receptor deficient MCF-7 cells. Br J Cancer 88: 599-605, 2003.

3. Bradshaw TD, Bibby MC, Double JA, et al: Preclinical evaluation of amino acid prodrugs of novel antitumor 2-(4amino-3-methylphenyl)benzothiazoles. Mol Cancer Ther 1: 239-246, 2002

4. Brantley E, Trapani V, Alley MC, et al: Fluorinated 2-(4-amino3-methylphenyl)benzothiazoles induce CYP1A1 expression, become metabolized, and bind to macromolecules in sensitive human cancer cells. Drug Metab Dispos 32: 1392-1401, 2004.

5. Leong CO, Gaskell M, Martin EA, et al: Antitumour 2-(4aminophenyl)benzothiazoles generate DNA adducts in sensitive tumour cells in vitro and in vivo. Br J Cancer 88: 470-477, 2003.

6. Leong CO, Suggitt M, Swaine DJ, Bibby MC, Stevens MF and Bradshaw TD: In vitro, in vivo, and in silico analyses of the antitumor activity of 2-(4-amino-3-methylphenyl)-5-fluorobenzothiazoles. Mol Cancer Ther 3: 1565-1575, 2004.

7. Jaffe EA, Nachman RL, Becker CG and Minick CR: Culture of human endothelial cells derived from umbilical veins. Identification by morphologic and immunologic criteria. J Clin Invest 52: 2745-2756, 1973.

8. Mukherjee A, Westwell AD, Bradshaw TD, Stevens MF, Carmichael J and Martin SG: Cytotoxic and antiangiogenic activity of AW464 (NSC 706704), a novel thioredoxin inhibitor: an in vitro study. Br J Cancer 92: 350-358, 2005.

9. Carmichael J, De Graff WG, Gazdar AF, Minna JD and Mitchell JB: Evaluation of a tetrazolium-based semiautomated colorimetric assay: assessment of chemosensitivity testing. Cancer Res 47: 936-942, 1987.

10. Carmichael J, De Graff WG, Gazdar AF, Minna JD and Mitchell JB: Evaluation of a tetrazolium-based semiautomated colorimetric assay: assessment of radiosensitivity. Cancer Res 47: 943-946, 1987.

11. Saunders DE, Lawrence WD, Christensen C, Wappler NL, Ruan H and Deppe G: Paclitaxel-induced apoptosis in MCF-7 breast-cancer cells. Int J Cancer 70: 214-220, 1997.

12. Liebmann JE, Cook JA, Lipschultz C, Teague D, Fisher J and Mitchell JB: Cytotoxic studies of paclitaxel (Taxol) in human tumour cell lines. Br J Cancer 68: 1104-1109, 1993.

13. Freshney RI: Culture of Animal Cells: A Manual of Basic Technique. 3rd edition. Wiley Liss, New York, pp200-201, 1994.
14. Dicker AP, Williams TL and Grant DS: Targeting angiogenic processes by combination rofecoxib and ionizing radiation. Am J Clin Oncol 24: 438-442, 2001.

15. Ponce ML: In vitro Matrigel angiogenesis assays. In: Angiogenesis Protocols. Murray JC (ed.) Humana Press, Totowa, NJ, pp205-212, 2000.

16. Banerjee S, Fallis AG and Brown DL: Differential effects of taxol on two human cancer cell lines. Oncol Res 9: 237-248, 1997.

17. Valenti AM, Niero A, Monti G, Marangolo F and Marangolo M: Paclitaxel and N-methylformamide: in vitro interactions in human colon cancer cell line. Anticancer Res 17A: 2491-2497, 1997.

18. Belotti D, Vergani V, Drudis T, et al: The microtubule-affecting drug paclitaxel has antiangiogenic activity. Clin Cancer Res 2: 1843-1849, 1996.

19. Iwahana M, Utoguchi N, Mayumi T, Goryo M and Okada K: Drug resistance and P-glycoprotein expression in endothelial cells of newly formed capillaries induced by tumors. Anticancer Res 18C: 2977-2980, 1998

20. Ingber D, Fujita T, Kishimoto S, et al: Synthetic analogues of fumagillin that inhibit angiogenesis and suppress tumour growth. Nature 348: 555-557, 1990

21. Hasan J, Shnyder SD, Bibby M, Double JA, Bicknel R and Jayson GC: Quantitative angiogenesis assays in vivo - a review. Angiogenesis 7: 1-16, 2004.

22. Takamiya Y, Brem H, Ojeifo J, Mineta T and Martuza RL: AGM-1470 inhibits the growth of human glioblastoma cells in vitro and in vivo. Neurosurgery 34: 869-875, 1994.

23. Chabner BA and Longo DL: Preclinical aspects of drug discovery and development. In: Cancer Chemotherapy and Biotherapy. 3rd edition. Lippincott, Williams and Wilikins, Philadelphia, PA, lwwoncology.com, 2002.

24. Annas A, Brittebo E and Hellman B: Evaluation of benzo(a) pyrene-induced DNA damage in human endothelial cells using alkaline single cell gel electrophoresis. Mutat Res 471: 145-155, 2000.

25. Stegeman JJ, Hahn ME, Weisbrod R, et al: Induction of cytochrome P4501A1 by aryl hydrocarbon receptor agonists in porcine aorta endothelial cells in culture and cytochrome P4501A1 activity in intact cells. Mol Pharmacol 47: 296-306, 1995.

26. Celander M, Weisbrod R and Stegeman JJ: Glucocorticoid potentiation of cytochrome P4501A1 induction by $2,3,7,8$ tetrachlorodibenzo-p-dioxin in porcine and human endothelial cells in culture. Biochem Biophys Res Commun 232: 749-753, 1997.

27. Chua MS, Kashiyama E, Bradshaw TD, Stinson SF, Brantley E, Sausville EA and Stevens MF: Role of Cyp1A1 in modulation of antitumor properties of the novel agent 2-(4-amino-3methylphenyl)benzothiazole (DF 203, NSC 674495) in human breast cancer cells. Cancer Res 60: 5196-5203, 2000.

28. Loaiza-Perez AI, Trapani V, Hose C, Singh SS, Trepel JB, Stevens MF and Bradshaw TD: Aryl hydrocarbon receptor mediates sensitivity of MCF-7 breast cancer cells to antitumor agent 2-(4-amino-3-methylphenyl) benzothiazole. Mol Pharmacol 61: 13-19, 2002.

29. Bradshaw TD, Chua MS, Orr S, Matthews CS and Stevens MF: Mechanisms of acquired resistance to 2-(4-aminophenyl)benzothiazole (CJM 126, NSC 34445). Br J Cancer 83: 270-277, 2000.

30. Fichtner I, Monks A, Hose C, Stevens MF and Bradshaw TD: The experimental antitumor agents Phortress and doxorubicin are equiactive against human-derived breast carcinoma xenograft models. Breast Cancer Res Treat 87: 97-107, 2004. 